\title{
Contribuciones a la flora vascular de la provincia de Málaga (Andalucía, España)
}

\author{
Federico Casimiro-Soriguer Solanas \& Baltasar Cabezudo \\ Área de Botánica (Departamento de Biología Vegetal). Facultad de Ciencias. Universidad de Málaga. Málaga.
}

\section{Correspondencia}

F. Casimiro-Soriguer Solanas

e-mail: fedeque@hotmail.com

Recibido: 11 junio 2018

Aceptado: 9 julio 2018

Publicado on-line: septiembre 2018
Contributions to the vascular flora of Malaga province (Andalusia, Spain)

Palabras clave: Flora vascular, corología, Málaga, Andalucía oriental

Key words: Vascular flora, chorology, Málaga, eastern Andalusia
Con el fin de ir recopilando información referente a la flora vascular de la provincia de Málaga y aprovechando el excelente año hidrológico 2017-2018, se herborizó en uno de los pequeños afloramientos de areniscas silíceas de la vertiente norte de los Montes de Málaga (La Axarquía, Málaga). Como resultado de las recolecciones efectuadas se han identificado una serie de especies que consideramos de interés por su rareza en la provincia de Málaga y en Andalucía Oriental, todas estas especies están ligadas a pastizales incluibles en la clase IsoetoNanojuncetea y correspondientes al Hábitat de Interes Comunitario Prioritario HIC 3170 - Directiva Hábitats (D. 92/43/CEE)-. Las especies ordenadas alfabéticamente se comentan a continuación junto con los datos de los pliegos testigo.

\section{Callitriche brutia Petagna}

Especie anual rara en Andalucía oriental y que se localizaba en Málaga solo en su parte aljíbica (Melendo \& Salazar, 2011). En la zona estudiada se presenta muy localizada en algunas pequeñas pozas temporales en los roquedos.

Málaga: Casabermeja, Montes de Málaga, Peñones de Cabrera, 30SUF7684, encinar con alcornoques, comunidad de macrófitos en pequeñas pozas excavadas en el roquedo, 580610 m., 15/4/2018, areniscas, F. Soriguer (MGC 87550).

\section{Crassula vaillantii (Willd.) Roth.}

Especie anual no citada con anterioridad en la provincia de Málaga (Fernandes, 1997) y rara en Andalucía Oriental (Giménez \& Cueto, 2011). En la zona estudiada aparece en las zonas más húmedas de trampales temporales y en pequeñas pozas temporales en los roquedos.

Málaga: Casabermeja, Montes de Málaga, Peñones de Cabrera, 30SUF7684, encinar con alcornoques, comunidad de macrófitos en pequeñas pozas excavadas en el roquedo, areniscas, 580-610 m., 15/4/2018, F. Soriguer (MGC 87535; MGC 87549).

\section{Isoetes hystrix Bory}

Especie que en Málaga solo estaba citada en la comarca del Aljibe (Cabezudo, 2011; Moreno Saiz et al., 2015), siendo rara en el resto de Andalucía Oriental (Moreno Saiz et al., 2015). En la zona estudiada es localmente abundante, llegando a formar pequeños prados ligados a trampales temporales.

Málaga: Casabermeja, Montes de Málaga, Peñones de Cabrera, 30SUF7684, encinar con alcornoques, trampales temporales, areniscas. 580-610 m., 15/4/2018, F. Soriguer (MGC 87533; MGC 87532).

\section{Molineriella minuta (L.) Rouy}

Especie anual muy rara en Andalucía Oriental, donde estaba citada solamente y de forma muy localizada en la Sierra Morena jiennense (Romero A. T., 2011; Cebrino \& Romero Zarco, 2017). En la zona estudiada aparece puntualmente formando parte de los pastizales efímeros ligados a trampales temporales. Novedad para la provincia de Málaga.

Málaga: Casabermeja, Montes de Málaga, Peñones de Cabrera, 30SUF7684, encinar con alcornoques, trampales temporales, areniscas, 580-610 m., 15/4/2018, F. Soriguer (MGC 87539)

\section{Ophioglossum lusitanicum $\mathrm{L}$.}

Especie muy localizada en la provincia de 
Málaga. Fue recolectada por primera vez en la comarca de la Axarquía en el año 1997 (Cabezudo, 2011), siendo la única cita de la zona. La especie no había vuelto a ser localizada desde entonces. Esta localidad no está recogida por Moreno Saiz et al., (2015), autores que solo recogen su presencia en el extremo occidental de la provincia. En la zona estudiada aparece puntualmente en pastizales efímeros sobre suelos arenosos húmedos.

Málaga: Casabermeja, ladera del río Guadalmedina, exposición norte. 30SUF7383, 22/10/1997. B. Cabezudo (MGC 46036-1); Ibidem. Montes de Málaga, Peñones de Cabrera, 30SUF7684, encinar con alcornoques, trampales temporales, areniscas, 580-610 m., 15/4/2018, F. Soriguer (MGC 87531).

Las especies citadas comparten su carácter efímero (al menos en sus partes aéreas), su pequeño tamaño y su hábitat ligado a suelos temporalmente encharcados, características que las han hecho pasar desapercibidas en trabajos anteriores (Pérez Latorre et al., 2008). Futuras prospecciones en hábitats similares, isleos rocosos de areniscas silíceas de la misma área geográfica (Axarquía y Corredor Colmenar-Periana) pueden dar una ampliación de su área de distribución.

\section{Agradecimientos}

A Carlos Romero Zarco por confirmar la identificación del material de Molineriella minuta que aparece en el texto.

\section{Bibliografía}

Cabezudo, B. (2011). Pteridofitos. En G. Blanca, G., Cabezudo, B., Cueto M., Morales Torres, C. \& Salazar, C. (Eds.). Claves de la Flora vascular de Andalucía Oriental (pp. 31-40). Granada, España. Universidades de Granada, Almería, Jaén y Málaga.

Cebrino Cruz, J. \& Romero-Zarco C. (2017). Revisión taxonómica del género Molineriella Rouy (Gramineae: Poeae: Airinae) en la Península Ibérica. Acta Botanica Malacitana 42, 201-212.

Fernandes, R.B. (1997). Crassula L. En Castroviejo, S. et al. (Eds.). Flora iberica 5 (pp. 99- 103). Madrid, España. Real Jardín Botánico. CSIC.

Giménez, E. \& Cueto, M. (2011). Crassulaceae En G. Blanca, Cabezudo, B., Cueto M., Morales Torres, C. \& Salazar, C. (Eds.). Claves de la Flora vascular de Andalucía Oriental (pp. 247- 250). Granada, España. Universidades de Granada, Almería, Jaén y Málaga.

Melendo, M. \& Salazar, C. (2011). Callitrichaceae En G. Blanca, Cabezudo, B., Cueto M., Morales Torres, C. \& Salazar, C. (Eds.). Claves de la Flora vascular de Andalucía Oriental (pp. 247- 250). Granada, España. Universidades de Granada, Almería, Jaén y Málaga.

Moreno Saiz, J. C., Pataro, L. \& Pajarón Sotomayor, S. (2015) Atlas de los pteridófitos de la Península Ibérica e Islas Baleares. Acta Botanica. Malacitana, 40, 5-55.

Pérez Latorre A. V., G. Caballero, F. Casimiro-Soriguer Solanas, O. Gavira \& B. Cabezudo (2008). Vegetación del sector Malacitano-Axarquiense (comarca de la Axarquía, Montes de Málaga y Corredor de Colmenar). Málaga (España). Acta Botanica Malacitana 33, 215270.

Romero A. T. (2011). Molineriella Rouy En G. Blanca, Cabezudo, B., Cueto M., Morales Torres, C. \& Salazar, C. (Eds.). Claves de la Flora vascular de Andalucía Oriental (pp. 147). Granada, España. Universidades de Granada, Almería, Jaén y Málaga. 